\title{
DETERMINAN CITRA HARGA DAN DAMPAKNYA TERHADAP NIAT PEMBELIAN
}

\author{
Hasan Ubaidillah \\ Fakultas Ekonomi dan Bisnis Universitas Muhammadiyah Sidoarjo \\ Jl. Mojopaht 666 B Sidoarjo
}

\begin{abstract}
Aim this study to examine the effect of price image on the intention to make a purchase in modern retail in the region Gedangan Sidoarjo. The population of this study is consumers who make purchases at five modern retail stores. The sampling technique using accidental sampling, analysis techniques with multiple regression analysis. The analysis showed that all independent variables price level perception, value for money, price processibility positive and significant effect on the intention of making a purchase and price perceptibility have no positive and significance effect on intention of making a purchase.
\end{abstract}

Keywords : Price Image, Buying Intention.

DOI : http://dx.doi.org/10.21067/jem.v12i3.1539

Diterima: September 2016; Direvisi: Oktober, 2016; Diterima : November 2016

\section{PENDAHULUAN}

Persaingan bisnis ritel dengan semakin banyaknya jumlah toko menyebabkan tingkat persaingan semakin meningkat. Analisis terhadap faktor-faktor yang menyebabkan konsumen melakukan pembelian merupakan hal penting untuk dipelajari. Salah satu faktor penting mempelajari perilaku konsumen adalah mengaitkan perilaku tersebut dengan harga. Harga merupakan determinan penting konsumen melakukan pembelian. Menurut (Kotler, 2001), harga merupakan sejumlah uang yang dibebankan atas suatu produk atau jasa, atau jumlah dari nilai yang ditukar konsumen atas manfaat-manfaat karena memiliki atau menggunakan produk atau jasa tersebut. Bagi retailer harga tidak hanya ditentukan dengan besar kecilnya jumlah uang yang ditukarkan untuk mendapatkan barang, namun harga merupakan suatu citra. Hal ini karena pembelian konsumen di toko didasarkan atas pengetahuan subjektif dan perasaan tentang aktivitas retailer menentukan

* Corresponding Author. ubaid@umsida.ac.id harga secara keseluruhan. (Zielke, 2006).

Bisnis retail menurut Kotler (2000) merupakan semua aktivitas yang melibatkan penjualan barang atau jasa pada konsumen akhir untuk dipergunakan yang sifatnya pribadi, bukan bisnis. Konsumen retail adalah konsumen akhir yang membeli barang tidak dalam jumlah besar, sehingga retailer namun harus menyediakan barang yang beragam sehingga menjamin ketersediaan barang yang dibutuhkan pelanggan agar pelanggan tidak perlu melakukan pembelian di tempat lain.

Keragaman jenis barang yang harus disediakan oleh pengecer setidaknya membawa akibat sulitnya menentukan harga yang tepat kepada konsumen agar toko tersebut dinilai murah oleh konsumen. Masyarakat yang mempunyai pendapatan menengah kebawah merupakan konsumen yang peka terhadap harga yang ditawarkan oleh pengecer dan berusaha membandingkan tingkat harga secara keseluruhan pada suatu toko dengan toko lainnya. Oleh karena itu, merupakan hal yang penting bagi retailer untuk mengetahui citra harga toko mereka karena membantu retailer untuk mengetahui mengukur harga yang telah ditetapkan dan harga yang 
dipersepsikan oleh konsumen, (Zielke, 2010). Harga murah belum belum tentu mempunyai citra harga baik, seperti dijelaskan oleh Brown (1969) bahwa perilaku pemilihan suatu toko lebih disebabkan kesan konsumen terhadap harga dari pada harga actual suatu toko. Membandingkan harga actual antar toko merupakan hal yang penting tapi hal tersebut belumlah cukup jika tidak mengetahui price image

\section{TINJAUAN PUSTAKA \\ Price Image}

Nystrom (1970) mendefinisikan price image (citra harga) sebagai sikap konsumen terhadap berbagai tingkat harga. Citra harga merupakan variabel laten multidimensi berupa keyakinan subyektif dan perasaan terkait penetapan harga oleh pengecer, (Murthi \& Rao, 2012; Zielke, 2006). Hamilton and Chernev (2013) menjelaskan price image merupakan kesan subyektif konsumen terhadap keseluruhan tingkat harga barang pengecer, yang merupakan evaluasi konsumen tentang harga barang dibandingkan dengan harga yang menjadi referensi.

Beberapa penelitian terdahulu menjelaskan konsep harga dalam beberapa kategori, Zeithaml (1988) mengkategorikan konstruk harga yang terdiri dari harga obyektif dan harga subyektif, menurut Schindler and Kibarian (2001) harga retail ditentukan oleh harga yang tertera di produk, Brown (1969) menjelaskan bahwa harga bukan merupakan aspek harga dalam bentuk nominal namun harga ditentukan oleh ukuran toko, design toko, dan tingkat layanan. walaupun terdapat beberapa perbedaan secara konseptual namun kesamaan dari beberapa penelitian tersebut adalah alasan pemilihan suatu toko lebih ditentukan oleh penilaian harga oleh konsumen dari pada harga aktual atau harga nominal produk. Oleh karena itu diperlukan konsep yang menyeluruh yang dapat menggambarkan penilaian harga konsumen. Zielke (2010) Menjelaskan bahwa citra harga pada sebuah toko retail ditentukan oleh price level perception, value for money, price processibility, price processibility, evaluation certainty.

Price level perception merupakan persepsi pelanggan terhadap harga tanpa memperhitungkan kualitas. K.N. Rajendran and Tellis (1994) menyatakan bahwa price level perception terjadi ketika konsumen membandingkan harga satu jenis barang dibandingkan dengan barang yang lain yang menjadi referensi konsumen. Alba, Broniarczyk, Shimp, and Urbany (1994) mengemukakan bahwa harga merupakan search atribut dan konsumen dapat mengamati perbedaan harga suatu merk dalam sebuah toko. Oleh karena itu ahli menyarankan persepsi harga barang juga dikaitkan dengan persepsi keseluruhan harga barang yang ada dalam sebuah took yang terdiri dari

Value for money merupakan trade off antara apa yang diberikan dan didapat oleh konsumen, (Zielke, 2010). Definisi yang sama diberikan oleh Zeithaml (1988) bahwa harga pada perspektif konsumen merupakan sesuatu yang dikorbankan untuk mendapatkan produk. Price perceptibility merupakan kemudahan konsumen untuk melihat atau mengamati harga-harga barang yang ada di toko, (Zielke, 2010), sebelumnya Zielke (2006) menyatakan price perceptibility terkait dengan pemberian harga (price labelling) yang mudah diamati oleh konsumen secara jelas oleh retailer.

Price processibility merujuk pada kemudahan konsumen untuk memproses harga, (Zielke, 2010). Price processibility tergantung dengan layout barang yang ada di toko. Pengecer dapat mengatur letak barang merk dan kualitas hampir sama secara berdekatan, agar konsumen tidak membutuhkan usaha (effort) yang lebih keras untuk membandingkan harga antar merk. Tata letak yang kurang baik menyebabkan konsumen semakin membutuhkan usaha (effort) yang keras untuk membandingkan antar harga barang yang ada di toko.informasi harga secara mendalam merupakan hal yang sulit. Hal ini terjadi harga antar jenis, tipe dan ukuran barang yang ada di toko retail sangat berangan.

Evaluation certainty sejauh mana konsumen dengan mudah untuk melakukan penilaian terhadap harga-harga yang ada di toko, (Zielke, 2010). Ketidakpastian konsumen dalam melakukan penilaian terhadap harga pada retail mungkin terjadi karena pengetahuan konsumen terbatas, disamping pemahaman informasi harga secara mendalam merupakan hal yang sulit, karena 
perubahan harga pada retail merupakan hal yang biasa untuk dilakukan retailer.

\section{Niat Pembelian}

Sikap oleh Ajzen and Fishbein (1970) dijelaskan sebagai keseluruhan evaluasi atas suatu obyek secara psikologis. Perilaku konsumen dapat bersifat terbuka atau tersembunyi, adapun perilaku yang tersembunyi disebut sebagai niat, Mowen and
Minor (2002) menjelaskan bahwa niat berperilaku (behavioral intention) sebagai niat konsumen berperilaku tertentu dalam mempertimbangkan pembelian, karakter dan penggunaan barang. Pada studi ini sikap tentang price image digunakan untuk memprediksi niat untuk melakukan pembelian. Berdasarkan pertimbangan teoritis diatas maka kerangka konseptual pada penelitian ini sebagai berikut :

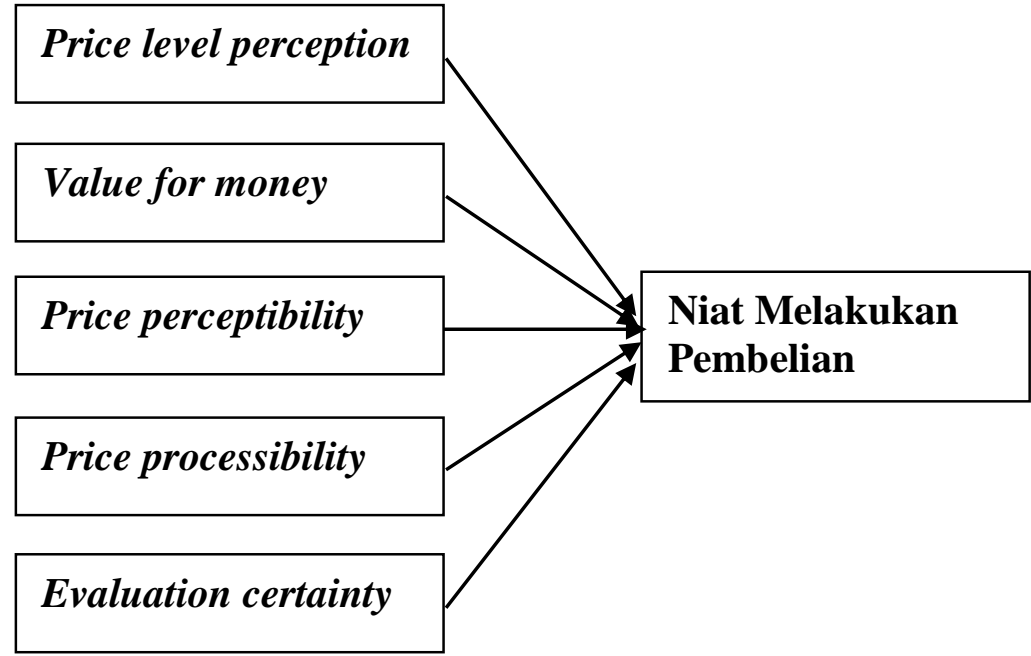

Gambar 1 : Kerangka Konseptual

\section{METODE}

Penelitian ini merupakan penelitian yang membuktikan hubungan kausal antara variabel bebas variabel price image yang diproksikan price level perception, value for money, price perceptibility, price processibility dan variabel terikat niat melakukan pembelian. Populasi dalam penelitian ini adalah konsumen yang melakukan pembelian di 5 Toko Retail Modern di Kawasan Gedangan Sidoarjo. Penelitian ini menggunakan accidental sampling, jumlah sampel ditentukan berdasarkan criteria bahwa pengambilan sampel sebanyak 5 sampai $10 \mathrm{kali}$ jumlah indikator. Pada penelitian ini jumlah indicator adalah sebanyak 14 sehingga jumlah sampel pada penelitian ini ditentukan sebanyak 75 konsumen.

\section{Definisi Operasional dan Pengukuran Variabel}

Adapun yang akan menjadi fokus penelitian adalah beberapa hal yang berkaitan dengan indikator permasalahan, yakni :

1) Price Image: a. Price level perception

1. Harga-harga di toko ini secara umum murah

2. Saya dapat membeli beberapa barang dengan harga murah di toko ini

3. Harga-harga barang yang ada di toko ini lebih murah dari pada di toko lain

b. Value for money

1. Harga-harga barang di toko ini sesuai dengan kualitas barangnya

2. Berbelanja di toko ini menurut saya lebih menguntungkan

3. Perbandingan antara harga dengan kualitas barang di toko ini lebih baik dari pada di toko lain

c. Price Perceptibility

1. Harga-harga yang ada di toko ini mudah untuk dilihat

2. Saya dapat dengan mudah membandingkan harga-harga barang yang berbeda yang dijual di toko ini

d. Price processibility 
1. Membandingkan harga-harga barang yang berbeda di toko ini merupakan usaha yang cukup berat bagi saya

2. Butuh waktu yang lama bagi saya untuk mengetahui barang di toko ini yang harganya sesuai dengan kualitasnya

\section{e. Evaluation certainty}

1. Saya menilai bahwa toko ini sangat baik dalam pemberian harga

2. Saya dapat dengan mudah menilai harga-harga yang ada di toko ini

2) Niat Melakukan Pembelian

a. Seharusnya saya berbelanja di toko ini sesering mungkin

b. Saya harus mempertimbangkan untuk berbelanja di toko ini

\section{HASIL DAN PEMBAHASAN Uji Instrumen}

Uji validitas dilakukan untuk melihat valid tidaknya masing-masing instrumen yang digunakan dalam variabel penelitian, keseluruhan butir dalam uji validitas dalam penelitian ini dinyatakan valid kecuali pada butir nomor 11 dan 12 karena nilai t hitung kurang dari $\mathrm{t}$ tabel, sehingga kedua item tersebut dikeluarkan dari model. Uji reliabilitas dari instrumen penelitian dengan mempertimbangkan besarnya koefesien reliabilitas, Sesuai dengan hasil analisa data primer maka instrumen yang digunakan dalam penelitian memiliki hasil uji yang menunjukkan angka cronbach alpha diatas 0,6 dari uji reliabilitas dapat dikatakan bahwa seluruh variabel yang digunakan dalam penelitian ini adalah reliabel.

\section{Perhitungan Koefisien Regresi}

Tahap selanjutnya adalah pendugaan parameter atau perhitungan koefisien path (jalur). Untuk pendugaan parameter dilakukan dengan analisis regresi melalui software SPSS 20 for windows. Hasil dari analisis substruktur persamaan disjikan pada lampiran dan tulis sebagai:

Berikut pada tabel 1 merupakan hasil perhitungan regresi linier berganda untuk mengetahui pengaruh/tidak, besarnya pengaruh antara variabel (Price Level Perception (X1), Value for Money (X2), Price perceptibility, (X3), Price Processibility (X4) terhadap Niat melakukan pembelian (Y)

Tabel 1:

Output Regresi Linier Berganda

\begin{tabular}{|c|c|c|c|c|c|c|}
\hline \multirow{3}{*}{$\begin{array}{l}\text { Variabel Independen } \\
\text { Sig.t }\end{array}$} & & \multicolumn{2}{|c|}{ Unstandardized } & \multicolumn{2}{|c|}{ Standardized } & \multirow[t]{2}{*}{ t-hitung } \\
\hline & & \multicolumn{2}{|c|}{ Coefficients } & \multicolumn{2}{|c|}{ Coefficients } & \\
\hline & & $B$ & Error & Beta & $t$ & Sig. \\
\hline (Constant) & & 1,263 & 0,918 & & 0,376 & 0,173 \\
\hline Price Level Perception & $\left(\mathrm{X}_{1}\right)$ & 0,215 & 0,078 & 0,257 & 2,750 & 0,008 \\
\hline Value for money & $\left(\mathrm{X}_{2}\right)$ & 0,152 & 0,062 & 0,304 & 2,467 & 0,016 \\
\hline Price Perceptibility & $\left(\mathrm{X}_{3}\right)$ & 0,112 & 0,093 & 0,105 & 1,200 & 0,234 \\
\hline Price Processibility & $\left(\mathrm{X}_{4}\right)$ & 0,292 & 0,116 & 0,289 & 2,515 & 0,014 \\
\hline
\end{tabular}

Variabel Dependent : Niat Melakukan Pembelian

Sumber: Data Diolah 2016

\section{Hasil Uji $\mathbf{R}^{2}$}

Koefesien determinasi atau $\mathrm{R}^{2}$ digunakan untuk menyatakan kecocokan model garis regresi. Besarnya harga koefisien determinasi dapat dilihat pada tabel 3. Diketahui koefisien $\mathrm{R}^{2}$ hitung (koefesien determinasi) sebesar 0,549, artinya dapat disimpulkan bahwa kemampuan variabel price image yang diproksikan dengan Price Level Perception, 
Value for Money, Price Perceptibility, Price Processibility, untuk menjelaskan variasi pada variabel niat melakukan pembelian adalah sebesar $54.9 \%$, sedangkan sisanya sebesar $45,1 \%$ niat melakukan melakukan pembelian di Kawasan Gedangan Sidoarjo dipengaruhi oleh faktor lain yang tidak dijelaskan dalam model regresi tersebut.

Tabel 2:

Ikhtisar Output Koefesien Determinasi

\begin{tabular}{lllll}
\hline $\mathbf{R}$ & $\mathbf{R}$ Square $\left(\mathbf{R}^{2}\right)$ & Adjusted R Square & $\mathbf{F}$-hitung & Sig. F \\
\hline 0,741 & 0,549 & 0,523 & 21,297 & 0,000 \\
\hline
\end{tabular}

Sumber: Data Diolah 2014

\section{Hasil Uji Hipotesis}

Uji Hipotesis Secara Parsial (Uji t)

Uji signifikan t-test antara Price Level Perception $\left(\mathrm{X}_{1}\right)$, terhadap niat melakukan pembelian (Y).

Hasil analisis di peroleh thitung Price Level Perception $\left(\mathrm{X}_{1}\right)$, sebesar 2,750 pada tingkat probabilitas 0,008 . Hasil pengujian diperoleh harga probabilitas hitung 0,008 < 0,05 atau probabilitas hitung < level of significance $(\alpha)$ sehingga $\mathrm{H}_{0}$ ditolak, hal ini berarti bahwa ada pengaruh signifikan dan positif antara Price Level Perception $\left(\mathrm{X}_{1}\right)$, terhadap niat melakukan pembelian $(\mathrm{Y})$ pada Toko Retail Modern Kawasan Gedangan Sidoarjo.

Uji signifikan t-test antara Value for Money $\left(\mathrm{X}_{2}\right)$, terhadap niat melakukan pembelian $(\mathrm{Y})$.

Hasil analisis di peroleh $t_{\text {hitung }}$ Value for Money $\left(\mathrm{X}_{2}\right)$ sebesar 2,467 pada tingkat probabilitas 0,016 . Hasil pengujian diperoleh harga probabilitas hitung $0,016<0,05$ atau probabilitas hitung < level of significance $(\alpha)$ sehingga $\mathrm{H}_{0}$ ditolak, hal ini berarti bahwa ada pengaruh signifikan dan positif antara Value for Money $\left(\mathrm{X}_{2}\right)$ terhadap niat melakukan pembelian (Y) pada Toko Retail Modern Kawasan Gedangan Sidoarjo.

Uji signifikan t-test antara Price Perceptibility $\left(\mathrm{X}_{3}\right.$ terhadap niat melakukan pembelian $(\mathrm{Y})$.

Hasil analisis di peroleh $t_{\text {hitung }}$ Price Perceptibility $\left(\mathrm{X}_{3}\right)$, sebesar 1,200 pada tingkat probabilitas 0,234 . Hasil pengujian diperoleh harga probabilitas hitung $0,234>0,05$ atau probabilitas hitung > level of significance $(\alpha)$ sehingga $\mathrm{H}_{0}$ diterima, hal ini berarti bahwa tidak ada pengaruh signifikan dan positif antara
Price Perceptibility $\left(\mathrm{X}_{3}\right)$ terhadap niat melakukan pembelian (Y) pada Toko Retail Modern Kawasan Gedangan Sidoarjo. Uji signifikan t-test antara Price Processibility $\left(\mathrm{X}_{4}\right)$ terhadap niat melakukan pembelian $(\mathrm{Y})$.

Hasil analisis di peroleh nilai $t_{\text {hitung }}$ Price Processibility $\left(\mathrm{X}_{4}\right)$ sebesar 2,515 pada tingkat probabilitas 0,014 . Hasil pengujian diperoleh harga probabilitas hitung 0,014 $<0,05$ atau probabilitas hitung < level of significance $(\alpha)$ sehingga $\mathrm{H}_{0}$ ditolak, hal ini berarti bahwa ada pengaruh signifikan dan positif antara Price Processibility $\left(\mathrm{X}_{4}\right)$ niat melakukan pembelian (Y) pada Toko Retail Modern Kawasan Gedangan Sidoarjo.

\section{Pengaruh Price Level Perception terhadap Niat Pembelian}

Variabel price level perception merupakan salah satu variabel yang mempengaruhi niat melakukan pembelian. Hasil dalam penelitian ini menunjukkan bahwa price level perception berpengaruh secara positif dan signifikan terhadap niat melakukan pembelian. Persaingan antar toko di kawasan Gedangan Sidoarjo sudah cukup tinggi yang menurut penulis disebabkan jumlah yang banyak dengan jarak antar toko dekat. Jumlah yang banyak disebabkan saat ini sudah tidak ada kesulitan bagi masyarakat untuk membuka Toko Retail Modern dimana selalu tersedia supplier yang siap untuk menyediakan stock. Stock yang beragam baik di dalam toko itu sendiri maupun toko yang lain memberikan kemudahan informasi bagi konsumen untuk membandingkan harga barang yang dibeli dengan harga barang dijadikan referensi. Penelitian ini sesuai dengan penelitian yang dilakukan oleh Zielke (2010) bahwa price level 
perception mempengaruhi niat untuk melakukan pembelian

\section{Pengaruh Value for money terhadap Niat Pembelian}

Variabel value for money merupakan salah satu variabel yang mempengaruhi niat melakukan pembelian. Hasil dalam penelitian ini menunjukkan bahwa value for money berpengaruh secara positif dan berpengaruh terhadap niat melakukan pembelian. Konsumen dengan segmen menengah ke bawah cenderung peka terhadap harga karena harga barang merupakan pengorbanan bagi konsumen ketika terjadi pembelian, sehingga konsumen akan selalu berupaya untuk mempertimbangkan kesamaan nilai antara barang yang dibeli dengan uang yang dikeluarkan. Pengaruh variabel value for money terhadap niat melakukan pembelian sesuai dengan penelitian yang dilakukan oleh Zeithaml (1988).

\section{Pengaruh Price Perceptibility terhadap Niat Pembelian}

Variabel price perceptibility merupakan salah satu variabel yang mempengaruhi niat melakukan melakukan pembelian. Hasil dalam penelitian ini menunjukkan bahwa price perceptibility berpengaruh secara positif namun tidak signifikan terhadap niat melakukan pembelian. Keragaman jenis barang baik menurut jenis ataupun merk tidak memungkinkan bagi retailer untuk memberikan label harga pada semua jenis atau merk barang karena toko relatif sempit. Konsumen akan bertanya kepada wiraniaga jika ingin mengetahui harga barang namun harga barang tersebut tidak di display. Pengaruh variabel price perceptibility terhadap niat melakukan pembelian sesuai dengan penelitian yang dilakukan oleh Zielke (2008).

\section{Pengaruh Price Processibility terhadap Niat Pembelian}

Variabel price processibility merupakan salah satu variabel yang mempengaruhi niat melakukan pembelian. Hasil dalam penelitian ini menunjukkan bahwa price processibility berpengaruh secara positif dan signifikan terhadap niat melakukan pembelian. Usaha (effort) yang dilakukan konsumen untuk membandingkan harga antar barang/merk ditentukan oleh layout (tata letak) barang yang ada di toko. Lay out (tata letak) yang sesuai dapat menjadikan konsumen tidak perlu usaha (effort) yang keras untuk membandingkan harga-harga barang yang ada di toko. Pengaruh variabel price proceesibility terhadap niat melakukan pembelian sesuai dengan penelitian yang dilakukan oleh (Zielke, 2010)

\section{KESIMPULAN}

Berdasarkan penelitian yang telah dilakukan oleh penulis mengenai pengaruh price image terhadap perilaku pinjaman di terhadap niat melakukan pembelian di Kawasan Gedangan Sidoarjo, maka kesimpulan pada penelitian ini adalah :

Price level perception berpengaruh secara positif dan signifikan terhadap niat melakukan pembelian di Kawasan Gedangan Sidoarjo. Value for money berpengaruh secara positif dan signifikan terhadap niat melakukan pembelian di Kawasan Gedangan Sidoarjo. Price Perceptibility berpengaruh secara positif dan tidak signifikan terhadap niat melakukan pembelian di Kawasan Gedangan Sidoarjo. Price Processibility berpengaruh secara positif dan signifikan terhadap niat melakukan pembelian di Kawasan Gedangan Sidoarjo.

Pada penelitian selanjutnya diharapkan lebih memberikan gambaran yang lengkap dan menyeluruh jika melibatkan lebih banyak variable dalam penelitiannya, setidaknya jumlah variabel pada price image baik sebagai antecedents maupun indikator sehingga dapat memberkan gambaran yang lebih komprehensif.

\section{Daftar Pustaka}

Ajzen, I., \& Fishbein, M. (1970). The prediction of behavior from attitudinal and normative variables. Journal of Experimental Social Psychology, 6(4), 466-487. doi:http://dx.doi.org/10.1016/0022$\underline{\text { 1031(70)90057-0 }}$

Alba, J. W., Broniarczyk, S. M., Shimp, T. A., \& Urbany, J. E. (1994). The Influence of Prior Beliefs, Frequency Cues, and Magnitude Cues on Consumers' Perceptions of Comparative Price Data. Journal of Consumer Research, 21(2), 219-235.

Brown, F. E. (1969). Price image versus price reality. Journal of marketing research, 6(2), 185-191. 
Hamilton, R., \& Chernev, A. (2013). Low Prices Are Just the Beginning: Price Image in Retail Management. Journal of Marketing, 77(November), 1-20.

K.N. Rajendran, \& Tellis, G. J. (1994). Contextual and temporal components of reference price. Journal of Marketing, 58(1), 22.

Kotler, P. (2001). Marketing Management (Millenium ed.). New Jersey: PrenticeHall, Inc.

Mowen, J. C., \& Minor, M. (2002). Perilaku Konsumen (5 ed.). Jakarta: Erlangga.

Murthi, B. P. S., \& Rao, R. C. (2012). Price Awareness and Consumers' Use of Deals in Brand Choice. Journal of Retailing, $\quad 88(1), \quad 34-46$. doi:10.1016/j.jretai.2011.07.001

Nystrom, H. (1970). Retail Pricing An Integrated Economics and Psychological Approach. Stockholm: The Economics Research Institute.

Schindler, R. M., \& Kibarian, T. M. (2001). Image Communicated by the Use of 99 Endings in Advertised Prices. Journal of Advertising, 30(4), 95-99. doi:10.1080/00913367.2001.1067365 4

Zeithaml, V. A. (1988). Consumer Perceptions of Price, Quality, and Value: A MeansEnd Model and Synthesis of Evidence. Journal of Marketing, 52(3), 2-22.

Zielke, S. (2006). Measurement of retailers' price images with a multiple-item scale. The International Review of Retail, Distribution and Consumer Research, 16(3), 297-316. doi:10.1080/09593960600696990

Zielke, S. (2010). How price image dimensions influence shopping intentions for different store formats. European Journal of Marketing, 44(6), 748-770. doi:10.1108/03090561011032702 